\title{
Ureido-Substituted Benzenesulfonamides Potently Inhibit Carbonic Anhydrase IX and Show Antimetastatic Activity in a Model of Breast Cancer Metastasis
}

\author{
Fabio Pacchiano, ${ }^{\dagger}$ Fabrizio Carta, ${ }^{\dagger}$ Paul C. McDonald, ${ }^{\ddagger}$ Yuanmei Lou, ${ }^{\ddagger}$ Daniela Vullo, ${ }^{\dagger}$ Andrea Scozzafava, ${ }^{\dagger}$ \\ Shoukat Dedhar, ${ }^{*,+, \S}$ and Claudiu T. Supuran ${ }^{*,+}$ \\ ${ }^{\dagger}$ Laboratorio di Chimica Bioinorganica, Rm. 188, Polo Scientifico, Università degli Studi di Firenze, Via della Lastruccia 3, 50019 Sesto \\ Fiorentino, Florence, Italy \\ ${ }^{\ddagger}$ Integrative Oncology, Cancer Research Centre and BC Cancer Agency, 675 West 10th Avenue, Vancouver, British Columbia, V5Z 1L3, \\ Canada \\ ${ }^{\S}$ Department of Biochemistry and Molecular Biology, University of British Columbia, Vancouver, British Columbia, Canada
}

Supporting Information

ABSTRACT: A series of ureido-substituted benzenesulfonamides was prepared that showed a very interesting profile for the inhibition of several human carbonic anhydrases (hCAs, EC 4.2.1.1), such as hCAs I and II (cytosolic isoforms) and hCAs IX and XII (transmembrane, tumor-associated enzymes). Excellent inhibition of all these isoforms has been observed with various members of the series, depending on the substitution pattern of the urea moiety. Several low nanomolar CA IX/XII inhibitors also showing good selectivity for the transmembrane over the cytosolic isoforms have been discovered. One of them, 4- $\left\{\left[\left(3^{\prime}\right.\right.\right.$-nitrophenyl)carbamoyl $]$ amino $\}$ benzenesulfonamide, significantly inhibited the formation of metastases by the highly aggressive 4T1 mammary tumor cells at pharmacologic concentrations of $45 \mathrm{mg} / \mathrm{kg}$, constituting an interesting candidate for the development of conceptually novel antimetastatic drugs.
A$$
\text { Vehi }
$$
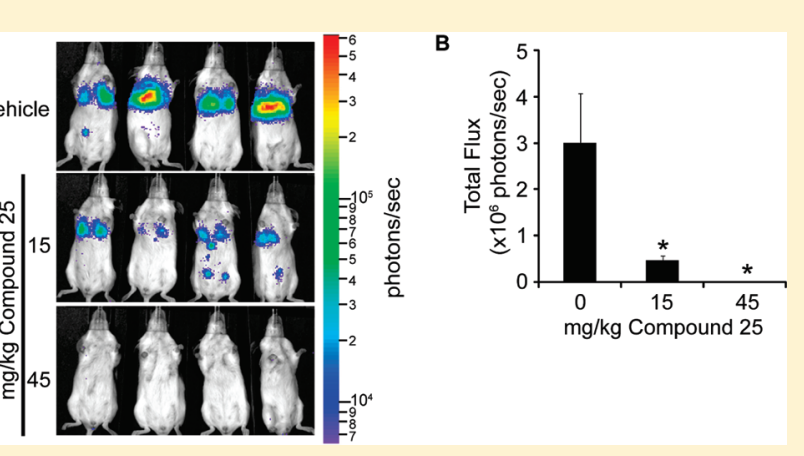

\section{INTRODUCTION}

Carbonic anhydrase (CA, EC 4.2.1.1) IX (CA IX) has recently been shown to be a druggable target for imaging and treatment of hypoxic tumors overexpressing this protein. ${ }^{1-6}$ CA IX is the most strongly overexpressed gene in response to hypoxia in human cancer cells. ${ }^{2-4}$ This enzyme is a multidomain protein ${ }^{2}$ with the CA subdomain situated outside the cell and possessing a very high $\mathrm{CO}_{2}$ hydrase catalytic activity, ${ }^{7}$ making it a key player in the regulation of tumor $\mathrm{pH}^{1-6} \mathrm{CA}$ IX expression is strongly increased in many types of solid tumors, such as gliomas/ependymomas, mesotheliomas, and papillary/follicular carcinomas; carcinomas of the bladder, uterine cervix, kidneys, esophagus, lungs, head and neck, breast, brain, and vulva; and squamous/basal cell carcinomas. ${ }^{8,9}$ Furthermore, such hypoxic tumors do not generally respond to the classic chemo- and radiotherapy. 8,9

Pouyssegur's group showed recently ${ }^{5}$ that in hypoxic LS174Tr tumor cells expressing either CA IX or both CA IX and CA XII isoforms, in response to a $\mathrm{CO}_{2}$ load, both enzymes contribute to extracellular acidification and to maintaining a more alkaline resting intracellular $\mathrm{pH}\left(\mathrm{pH}_{\mathrm{i}}\right)$, an action that preserves ATP levels and cell survival in a range of acidic outside $\mathrm{pH}(6.0-6.8)$ and low bicarbonate medium. In vivo experiments showed that silencing of CA IX alone leads to a $40 \%$ reduction in xenograft tumor volume, with up-regulation of the second gene, that encoding for CA XII. Silencing of both CA IX and CA XII gave an impressive $85 \%$ reduction of tumor growth. ${ }^{5}$ Hypoxiainduced CA IX and CA XII are major tumor prosurvival $\mathrm{pH}$ regulating enzymes, and their combined inhibition held potential for the design of anticancer drugs with a novel mechanism of action. The in vivo proof-of-concept study that sulfonamide CA IX inhibitors may indeed show antitumor effects has been only very recently published by Neri's group. ${ }^{6 a}$ Membrane-impermeable derivatives based on the acetazolamide AAZ scaffold to which either fluorescein carboxylic acid or albumin-binding moieties were attached have been employed. A strong tumor growth retardation in animals treated for 1 month with these CA inhibitors (CAIs) in mice with xenografts of a renal clear cell carcinoma line, SK-RC-52, was observed. ${ }^{6}$ Such data show the great promise of tumor growth inhibition with sulfonamides acting as CA IX/XII inhibitors. ${ }^{1}$ The same group reported the

Received: December 2, 2010

Published: March 01, 2011 
proof-of-concept study showing that human monoclonal antibodies targeting CA IX can also be used for imaging of hypoxic tumors. ${ }^{6 \mathrm{~b}}$ The generation of high-affinity human monoclonal antibodies (A3 and CC7) specific to hCA IX, using phage technology, has been recently reported. ${ }^{6 \mathrm{~b}}$ These antibodies were able to stain CA IX ex vivo and to target the cognate antigen in vivo. In one studied animal model of colorectal cancer (LS174T), CA IX imaging closely matched pimonidazole staining, with a preferential staining of tumor areas characterized by little vascularity and low perfusion. ${ }^{\text {b }}$ The same conclusion has been reached by our group by using small molecule CA IX selective inhibitors of the type 1 . $^{3}$ Fluorescent sulfonamides 1 with a high affinity for CA IX have been developed and shown to bind to cells only when CA IX protein was expressed and while cells were hypoxic. NMRI-nu mice subcutaneously transplanted with HT-29 colorectal tumors were treated with $7 \%$ oxygen or with nicotinamide and carbogen and were compared with control animals. Accumulation of compound $\mathbf{1}$ was monitored by noninvasive fluorescent imaging. Specific accumulation of $\mathbf{1}$ could be observed in delineated tumor areas compared with a structurally similar non-sulfonamide analogue incorporating the same scaffold 2. Administration of nicotinamide and carbogen, decreasing acute and chronic hypoxia, respectively, prevented accumulation of $\mathbf{1}$ in the tumor. When treated with $7 \%$ oxygen breathing, a 3-fold higher accumulation of 1 was observed. Furthermore, the bound inhibitor fraction was rapidly reduced upon tumor reoxygenation. ${ }^{3}$ Such in vivo imaging results confirm previous in vitro data demonstrating that CAI binding and retention require exposure to hypoxia. Labeled sulfonamide CAIs may provide a powerful tool to visualize hypoxia response in solid tumors. An important step was thus made toward clinical applicability, indicating the potential of patient selection for CA IX directed therapies. ${ }^{3}$

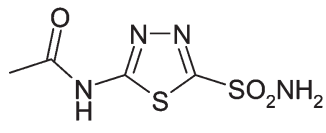

AAZ<smiles>[R]c1ccc(CNC(=S)Nc2ccc(-c3c4ccc(=O)cc-4oc4cc(O)ccc34)c(C(=O)O)c2)cc1</smiles>

1: $\mathrm{R}=\mathrm{SO}_{2} \mathrm{NH}_{2}$

2: $\mathrm{R}=\mathrm{H}$
One main draw-back of classical sulfonamide CAIs (such as AAZ) is the lack of selectivity for inhibiting CA IX over the other CA isoforms present in humans (15 isoforms, CAs I-XIV, are present in primates and 16 isoforms, i.e., CAs $\mathrm{I}-\mathrm{XV}$, in other vertebrates). ${ }^{1}$ Thus, it is crucial to explore chemotypes possessing a more selective inhibition profile against the target isoforms, e.g., with selectivity for the inhibition of the tumor-associated over other CA isoforms. A small series of five 4-RNHCONHsubstituted benzenesulfonamide derivatives was recently investigated as inhibitors of the cytosolic isoform hCA II ( $\mathrm{h}=$ human) by one of these groups. ${ }^{10}$ It has been observed that their potency varied between 3.3 and $226 \mathrm{nM}$, and by means of X-ray crystallography a highly variable orientation of the R-ureido moieties was evidenced when the inhibitor was bound within the enzyme active site (Figure 1). ${ }^{10}$ The $\mathrm{R}$ moieties were not disordered in

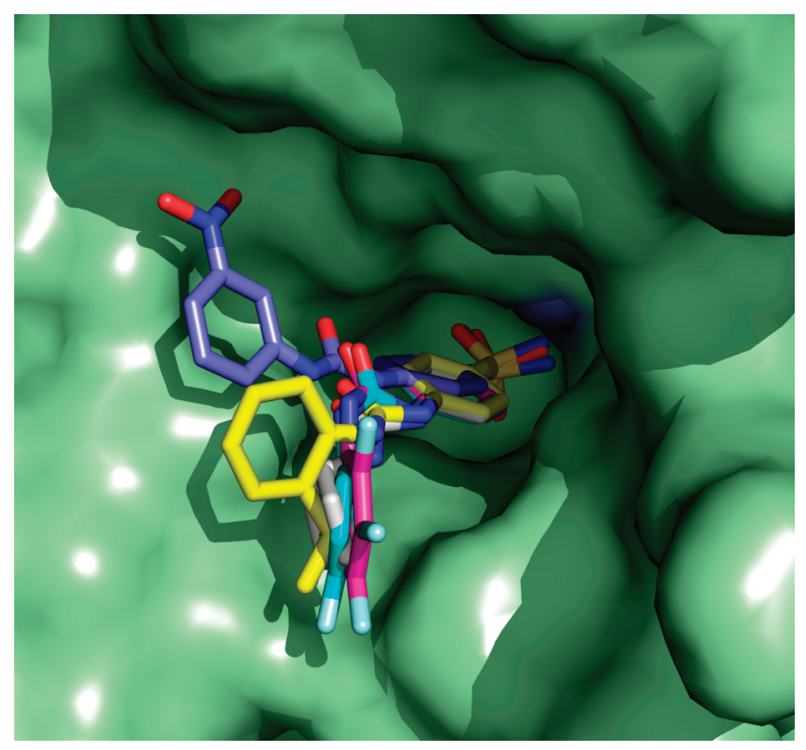

Figure 1. Binding of ureido-substituted benzenesulfonamides to the hCA II active site. The benzenesulfonamide moiety of five inhibitors is totally superposable, whereas the RNHCONH tails adopt different orientations in various subpockets of the active site $(\mathrm{R}=3$-nitrophenyl, violet; $\mathrm{R}=2$-isopropylphenyl, yellow; $\mathrm{R}$ = pentafluorophenyl, magenta; $\mathrm{R}=$ 4-fluorophenyl, sky blue; $\mathrm{R}=$ cyclopentyl, gray). ${ }^{10}$ The PDB entries of these structures are $3 \mathrm{~N} 4 \mathrm{~B}, 3 \mathrm{~N} 0 \mathrm{~N}, 3 \mathrm{~N} 3 \mathrm{~J}, 3 \mathrm{~N} 2 \mathrm{P}$, and $3 \mathrm{MZL}$, respectively. ${ }^{10}$

the X-ray crystal structures, but they adopted diverse orientations based on their specific chemical nature (Figure 1). Furthermore, a strong correlation has been observed between the binding pattern and $\mathrm{R}$ group orientation and the CA II inhibitory properties for this small library of compounds, where $\mathrm{R}$ was 4-fluorophenyl, pentafluorophenyl, 2-isopropylphenyl, 3-nitrophenyl, and cyclopentyl. ${ }^{10}$

In this paper we report the synthesis of a larger series of such ureido-substituted sulfonamide CAIs that possess strong affinity for CA IX, an acceptable selectivity profile for inhibiting the tumor-associated isoforms CAs IX and XII over the cytosolic ones CAs I and II, and excellent in vivo antimetastatic effects in a breast cancer xenograft model.

\section{RESULTS AND DISCUSSION}

Chemistry. In a recent work ${ }^{10}$ we showed that benzenesulfonamides incorporating 4-substituted ureido moieties act as hCA II inhibitors with potencies that correlate well with the orientation of the $\mathrm{R}$ moiety present in the ureido tail of the compound (Figure 1). As other classes of ureido-substituted benzenesulfonamides have been reported earlier, ${ }^{1,12}$ and we observed that they may lead to isoform-selective compounds, ${ }^{12}$ we decided to investigate in greater detail such derivatives. We report here the synthesis of a large series of 4-ureidosubstituted-benzenesulfonamides 4-30 prepared by reaction of sulfanilamide 3 with aryl/ alkyl isocyanates A1-A27 (Scheme 1). The chemical diversity was generated by varying the nature of the starting isocyanate, A1-A27 (Table 1). The CA isoforms have differing amino acid sequences in the external portion of their active sites; therefore, compounds with a better selectivity profile for the various isoforms will contain an $\mathrm{R}$ group moiety that can interact with this region. ${ }^{13}$ This has been reported earlier by our group, ${ }^{12}$ with 
Scheme 1. Preparation of the 4-Ureidosubstituted Benzenesulfonamides 4-30 from Sulfanilamide 3 and Isocyanates A1-A27

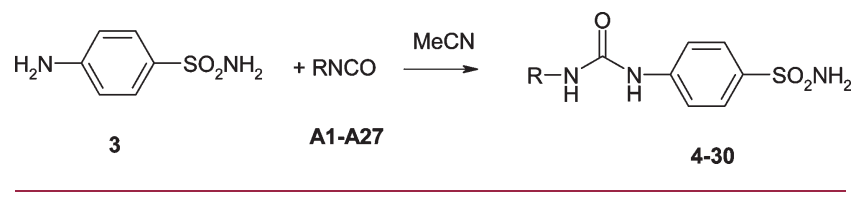

the observation that some ureido-substituted sulfonamides show selective inhibition of isoform hCA I over the dominant one hCA II.

As shown in Scheme 1 and Table 1, a large variety of aromatic and aliphatic $\mathrm{R}$ moieties have been incorporated in the new CAIs 4-30 reported here, in order to have an extensive structureactivity relationship (SAR) insight regarding their interactions with various CA isoforms with medicinal chemistry relevance. The synthesis of such compounds is a one-step process, generally occurring in high yield, allowing for the preparation of a large number of derivatives. Most of the CAIs of sulfonamide type investigated earlier contained $\mathrm{CONH}$ or $\mathrm{SO}_{2} \mathrm{NH}$ linkers between the sulfonamide head moiety and the tail instead of the ureido one present in 4-30. These different linkers allow less flexibility for the inhibitor scaffold, and this is probably the reason why such sulfonamides bind in the cannonical hydrophobic pocket of hCA II. ${ }^{13,14}$ They also generally do not show isoform selectivity. ${ }^{10}$ In contrast, for derivatives incorporating the ureido linker (of type 4-30), it has been shown ${ }^{10}$ that the tails (all of them well ordered in the crystal structures; see Figure 1) are found in various hydrophobic pockets of the CA II active site. As seen from the crystallographic data (Figure 1), ${ }^{10}$ the torsion angles between these two fragments of the scaffold were quite different for the five compounds investigated by X-ray crystallography (i.e., 7, 13, 16, 25, and 28). ${ }^{10}$ This probably allows the flexibility of the inhibitor to select the hydrophobic subpocket in such a way to avoid steric clashes ${ }^{10,13,14}$ and to make as many as possible favorable interactions with amino acid residues within the enzyme cavity.

CA Inhibition. Inhibition of four physiologically relevant $\alpha$-CA isoforms with compounds $4-30$ and acetazolamide (5-acetamido-1,3,4-thiadiazole-2-sulfonamide, AZA, a clinically used drug) is presented in Table $1 .{ }^{15}$ hCAs I and II (cytosolic, widespread enzymes) and hCAs IX and XII (transmembrane, tumor-associated CAs) have been included in this study because of their relevance as targets/offtargets when developing CAIs. Indeed, CA II for example is the drug target for developing antiglaucoma CAIs, ${ }^{1}$ but it is an off-target when considering CA IX/XII inhibition. ${ }^{1-3}$ In this latter case, only the transmembrane, tumor-associated isozymes (IX and XII) should be inhibited, as CA II may have the function of housekeeping enzyme and its inhibition may lead to side effects. ${ }^{1-3}$

The following structure-activity relationship (SAR) can be observed from data of Table 1 for the series of ureidosulfonamides 4-30 investigated here.

(i) The slow cytosolic isoform hCA I was inhibited by compounds $4-30$ with a wide range of potency, with inhibition constants in the range $9.0-5530 \mathrm{nM}$. Potent hCA I inhibition has been observed with the following compounds: 11, 16, 19, 22, and 30. These compounds incorporate 2- or 4-substuted phenyl moieties (such as 4-trifluoromethylphenyl, 2-isopropylphenyl, 4-n-butoxyphenyl, and 2-cyanophenyl) except 30 which
Table 1. Inhibition of hCAs I and II (Cytosolic Isoforms) and hCAs IX and XII (Transmembrane, Tumor-Associated Enzymes) with Ureidosulfonamides 4-30 and Acetazolamide AAZ as Standard ${ }^{15}$

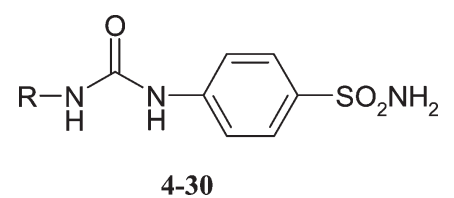

\begin{tabular}{|c|c|c|c|c|c|}
\hline \multirow[b]{2}{*}{ compd } & \multirow[b]{2}{*}{$\mathrm{R}$} & \multicolumn{4}{|c|}{$K_{\mathrm{I}}(\mathrm{nM})$} \\
\hline & & hCA I & hCA II & hCA IX & hCA XI \\
\hline 4 & $\mathrm{Ph}$ & 760 & 3730 & 575 & 67.3 \\
\hline 5 & $\mathrm{PhCH}_{2}$ & 92 & 2200 & 41.4 & 49.5 \\
\hline 6 & $\mathrm{Ph}_{2} \mathrm{CH}$ & 83 & 3725 & 58.8 & 64.5 \\
\hline 7 & $4-\mathrm{FC}_{6} \mathrm{H}_{4}$ & 5080 & 96 & 45.1 & 4.5 \\
\hline 8 & $\mathrm{Cl}-\mathrm{FC}_{6} \mathrm{H}_{4}$ & 2150 & 781 & 58.0 & 5.3 \\
\hline 9 & 4- $\mathrm{BrC}_{6} \mathrm{H}_{4}$ & 1465 & 1290 & 69.3 & 7.9 \\
\hline 10 & $4-\mathrm{IC}_{6} \mathrm{H}_{4}$ & 5500 & 2634 & 24.5 & 4.3 \\
\hline 11 & $4-\mathrm{CF}_{3} \mathrm{C}_{6} \mathrm{H}_{4}$ & 9.7 & 1150 & 6.2 & 2.3 \\
\hline 12 & $3,5-\left(\mathrm{CF}_{3}\right)_{2} \mathrm{C}_{6} \mathrm{H}_{3}$ & 3690 & 75 & 53 & 39 \\
\hline 13 & $\mathrm{C}_{6} \mathrm{~F}_{5}$ & 2395 & 50 & 5.4 & 5.1 \\
\hline 14 & $2-\mathrm{MeOC}_{6} \mathrm{H}_{4}$ & 92 & 4070 & 465 & 61.2 \\
\hline 15 & 4- $\mathrm{AcC}_{6} \mathrm{H}_{4}$ & 388 & 1060 & 5.4 & 4.6 \\
\hline 16 & $2-i-\mathrm{PrC}_{6} \mathrm{H}_{4}$ & 9.0 & 3.3 & 0.5 & 4.2 \\
\hline 17 & $4-i-\operatorname{PrC}_{6} \mathrm{H}_{4}$ & 4330 & 5005 & 541 & 49.7 \\
\hline 18 & $4-n-\mathrm{BuC}_{6} \mathrm{H}_{4}$ & 5530 & 2485 & 376 & 28.5 \\
\hline 19 & $4-n-\mathrm{BuOC}_{6} \mathrm{H}_{4}$ & 11.3 & 2.1 & 0.8 & 2.5 \\
\hline 20 & 4- $n$-octyl- $\mathrm{C}_{6} \mathrm{H}_{4}$ & 536 & 9600 & 47.1 & 52.8 \\
\hline 21 & $4-\mathrm{NCC}_{6} \mathrm{H}_{4}$ & 57.0 & 64.7 & 6.0 & 6.5 \\
\hline 22 & $2-\mathrm{NCC}_{6} \mathrm{H}_{4}$ & 10.9 & 2.4 & 0.3 & 4.6 \\
\hline 23 & 4- $\mathrm{PhOC}_{6} \mathrm{H}_{4}$ & 604 & 85 & 69.1 & 7.1 \\
\hline 24 & 2- $-\mathrm{PhC}_{6} \mathrm{H}_{4}$ & 1170 & 9.7 & 65.7 & 65.1 \\
\hline 25 & $3-\mathrm{O}_{2} \mathrm{NC}_{6} \mathrm{H}_{4}$ & 23.4 & 15 & 0.9 & 5.7 \\
\hline 26 & 4-MeO-2- $\mathrm{MeC}_{6} \mathrm{H}_{3}$ & 89.2 & 3310 & 73.3 & 6.0 \\
\hline 27 & $9 H$-fluoren-2-yl & 1700 & 908 & 102 & 55.4 \\
\hline 28 & cyclopentyl & 470 & 226 & 7.3 & 7.0 \\
\hline 29 & $3,5-\mathrm{Me}_{2} \mathrm{C}_{6} \mathrm{H}_{3}$ & 6530 & 1765 & 6.9 & 6.2 \\
\hline 30 & indan-5-yl & 9.8 & 8.9 & 7.0 & 2.5 \\
\hline AAZ & & 250 & 12 & 25 & 5.7 \\
\hline
\end{tabular}

possesses an indane moiety. It is thus clear, as in the crystallographic work reported earlier ${ }^{10}$ for 5 of the 27 derivatives reported here, that the nature of the $\mathrm{R}$ moiety present in these ureidosulfonamiodes is the main player influencing potency against all investigated CA isoforms. Indeed, a number of these derivatives, including $5,6,14,4,25$, and 26 , behaved as medium potency hCA I inhibitors with $K_{\mathrm{I}}$ in the range $23.4-92 \mathrm{nM}$. Again the nature of the $\mathrm{R}$ moieties present in these compounds was rather variable (benzyl, diphenylmethyl, and 2-, 3-, or 4-substituted phenyls). The remaining derivatives showed a decreased affinity for hCA I, with $K_{\mathrm{I}}$ in the range $388-5530$ nM. AAZ is similar to these compounds, with an inhibition constant of $250 \mathrm{nM}$ against hCA I (Table 1). 
(ii) The second offtarget isoform, the cytosolic hCA II, has also been inhibited with potencies ranging from the low nanomolar to the micromolar by ureidosulfonamides 4-30 (Table 1). Thus, compounds $16,19,22,24$, and 30 were very potent hCA II inhibitors, with $K_{\mathrm{I}}$ in the range $2.1-9.7 \mathrm{nM}$. These derivatives incorporate 2- or 4-substituted phenyl moieties or the indane ring. It is interesting to note that 16 and 19 contain in their molecule the rather bulky, lipophilic i-Pr, n-BuO, or biphenyl moieties, which one could consider to be too bulky to fit well within the hCA II active site. However, as shown here and in the crystallographic, preliminary communication, ${ }^{10}$ the $i$-Pr moiety of 16 makes hydrophobic contacts in a patch within the enzyme active site never seen earlier to accommodate inhibitors, also making a stacking with Phe131. This particular binding mode thus explains the excellent hCA II inhibitory of 16. However, four other derivatives of the series investigated here, i.e., 7, 13, 25, and 28, exploited different binding pockets within the enzyme active site ${ }^{10}$ and also possessed diverse inhibitory power. Another series of compounds showed medium potency hCA II inhibition, with $K_{\mathrm{I}}$ in the range $15-96 \mathrm{nM}$. These compounds $(7,12,13,21,23$, and 25) also possess aromatic groups at the second nitrogen ureido group, such as 4-fluorophenyl, 3,5-di(trifluoromethyl)phenyl, pentafluorophenyl, 4-cyanophenyl, 4-phenoxyphenyl, or 3-nitrophenyl. The remaining derivatives showed lower hCA II inhibitory properties, with $K_{\mathrm{I}}$ in the range $226-9600 \mathrm{nM}$. The least effective hCA II inhibitor was the derivative incorporating the long 4-noctylphenyl moiety (20).

(iii) The tumor-associated hCA IX was generally better inhibited by these compounds compared to hCAs I and II discussed above, with $K_{\mathrm{I}}$ in the range $0.3-575 \mathrm{nM}$. Compounds such as $11,13,15,16,19,21,22,25,28$, and 29 showed excellent hCA IX inhibiting properties, with $K_{\mathrm{I}}$ in the range $0.3-7.3 \mathrm{nM}$. A few weak hCA IX inhibitors were detected (e.g., 4, 14, 18, and 27 ), with $K_{\mathrm{I}}$ in the range $102-575 \mathrm{nM}$, whereas all other derivatives presented inhibition constants of $<100 \mathrm{nM}$. Substitution patterns favorable to potent hCA IX inhibition include the presence of 4-trifluoromethylphenyl, pentafluorophenyl, 4-acetylphenyl, 2-isopropylphenyl, 4- $n$-butoxyphenyl, 2- and 4-cyanophenyl, 3-nitrophenyl, cyclopentyl, and 3,5-dimethylphenyl moieties. However, most of the other substitution patterns present in the remaining compounds lead to effective hCA IX inhibitors, with $K_{\mathrm{I}}$ in the range $24.5-73.3 \mathrm{nM}$. AAZ was an effective hCA IX inhibitor too, with a $K_{\mathrm{I}}$ of $25 \mathrm{nM}$ (Table 1).

(iv) hCA XII was also effectively inhibited by sulfonamides 430 , with $K_{\mathrm{I}}$ in the range $2.3-67.3 \mathrm{nM}$. This was the isoform with the highest affinity for these compounds, as most of them were excellent inhibitors. Inhibition constants of $<10 \mathrm{nM}$ have been observed with a rather large number of compounds, among which are $7-11,13,15,16,19,21,25,26,28-30$, and AAZ. Thus, many substitution patterns lead to very effective hCA XII inhibitors in this congeneric series investigated here. The excellent inhibition of all CA isoforms investigated here and also the variability in inhibitory power for the various members of this congeneric series are phenomena never observed earlier for any class of CAIs investigated in detail and are probably due to the presence of the ureido linker in these molecules, which leads to the binding of the compound in multiple ways to the enzymes active sites.

(v) The selectivity ratio for inhibiting the target over the offtarget isoforms for this congeneric series of sulfonamides is rather complex because of the factors mentioned above. However, some interesting findings emerged. For example, compound $\mathbf{1 5}$ has a selectivity ratio of 71.8 for inhibiting CA IX over CA I and of 196.3 for inhibiting CA IX over CA II (the corresponding ratios for inhibiting CA XII over CAs I and II are even better), thus being a selective inhibitor of the tumorassociated isoforms over the cytosolic ones. Compound 25 was a stronger inhibitor of the cytosolic isoforms compared to $\mathbf{1 5}$ and had good selectivity ratio for inhibiting the tumor-associated isoforms over the cytosolic isoforms.

Antimetastatic Effects of CA IX Inhibitors. CA IX is highly expressed in breast malignancies, ${ }^{16}$ and studies have demonstrated that CA IX and CA XII are variably expressed in breast cancer cell lines. ${ }^{8}$ Furthermore, CA IX is associated with a poor prognosis for patients with breast cancer ${ }^{17}$ and it is significantly associated with distant metastasis (Lou et al., unpublished results). Therefore, we have chosen breast cancer as a malignancy model in which to test, in vivo, the antimetastatic activity of some of the CA IX inhibitors described here. Specifically, we have used the $4 \mathrm{~T} 1$ syngeneic mouse mammary tumor model. ${ }^{18} 4 \mathrm{~T} 1$ cells are highly tumorigenic and metastasize spontaneously to multiple sites in a manner similar to that for human breast cancer following orthotopic implantation into an immunocompetent host. ${ }^{18,19}$ We have shown recently that 4T1 tumors overexpress $\mathrm{CA} \mathrm{IX}^{20}$ and that these cells induce CA IX during hypoxia in vitro (Lou et al., unpublished results). These attributes make the 4T1 mouse mammary tumor cells a good model in which to examine the effects of inhibiting CA IX activity on breast cancer metastasis.

Although the 4T1 tumor model can be used to evaluate spontaneous metastatic events subsequent to tumor implantation and growth, such studies are lengthy and require surgical removal of the primary tumor. Because we were interested in evaluating the effect of the compounds on metastasis specifically, we elected to test the inhibitors using an experimental metastasis approach. Two compounds were chosen for the in vivo studies, 15 and 25, both of which show good CA IX and XII inhibitory activities and acceptable selectivity ratios for inhibiting the tumor-associated over the cytosolic isoforms, as discussed above. We injected 4T1 cells expressing luciferase intravenously and assessed the ability of the cells to form lung metastases after treating with compounds $\mathbf{1 5}$ (Figure 2) and $\mathbf{2 5}$ (Figure 3) using bioluminescent imaging techniques. Mice were treated with the inhibitors or equal amounts of vehicle beginning $24 \mathrm{~h}$ after injection of cells, and metastases were imaged the day following the final dose of inhibitor. We found that whereas treatment with $\mathbf{1 5}$ was not able to decrease the metastatic burden relative to the vehicle control group (Figure 2), treatment with 25 was effective in limiting colonization of the cells in the lungs in a dose-dependent fashion (Figure 3). Quantification of the bioluminescent signal revealed a statistically significant decrease in the formation of metastases in the mice administered $\mathbf{2 5}$ (Figure 3), while no significant differences were observed among the vehicle and 15-treated groups (Figure 2). Importantly, administration of the inhibitors did not result in significant weight loss in any animals, indicating that the inhibitors were not generally toxic (Supporting Information Figure 1). These data show that some of the ureidosulfonamide inhibitors of CA IX reported here are effective in attenuating formation of metastases in a model of aggressive breast cancer. It is interesting to note that even if $\mathbf{1 5}$ and $\mathbf{2 5}$ showed comparable CA inhibitory activity in vitro, $\mathbf{1 5}$ was ineffective in vivo probably because of pharmacokinetic reasons. The pharmacokinetic evaluation for some of these derivatives is in a preliminary stage, but we suspect 

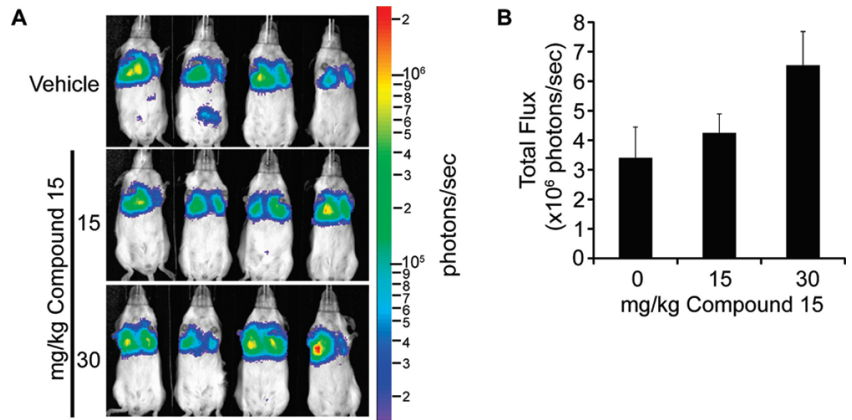

Figure 2. Ureidosulfonamide $\mathbf{1 5} \mathrm{did}$ not reduce the formation of metastase by $4 \mathrm{~T} 1$ mammary tumor cells. (A) 4T1 cells were injected directly into the tail vein of $\mathrm{BALB} / \mathrm{c}$ mice. Mice then received vehicle or 15 starting $24 \mathrm{~h}$ after injection of cells. Animals received therapy every day, and five doses were provided. Bioluminescent images were acquired $24 \mathrm{~h}$ after the final dose of inhibitor. (B) Quantification of bioluminescence: $n=6$ per group. No significant differences were observed among the vehicle inhibitor-treated groups.
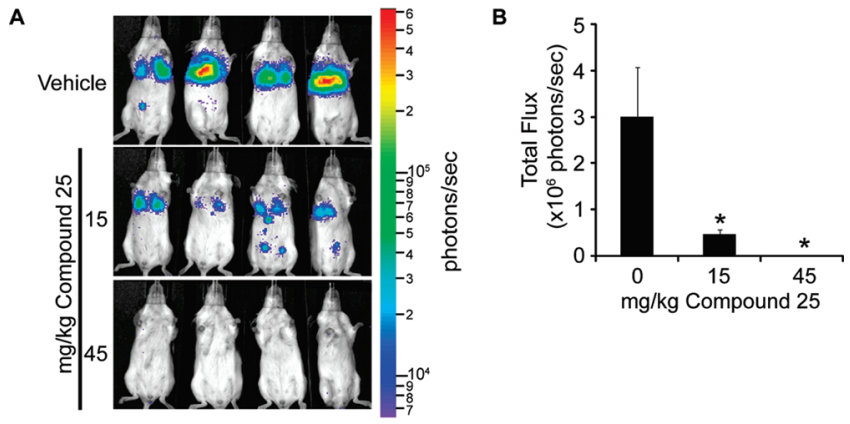

Figure 3. Ureidosulfonamide 25 inhibits the formation of metastases by 4T1 mammary tumor cells. (A) 4T1 cells were injected directly into the tail vein of BALB/c mice. Mice then received vehicle or 25 starting $24 \mathrm{~h}$ after injection of cells. Animals received therapy every other day, and three doses were provided. Bioluminescent images were acquired $24 \mathrm{~h}$ after the final dose of inhibitor. (B) Quantification of bioluminescence: $n=4$ per group; $*, p<0.05$.

that the acetyl moiety of $\mathbf{1 5}$ may undergo metabolic oxidation to the corresponding carboxylate followed by its conjugation and rapid elimination, which may explain its lack of antimetastatic effects compared to the highly efective $\mathbf{2 5}$ which is metabolically stable.

\section{CONCLUSIONS}

We report here a series of sulfonamides prepared by reaction of sulfanilamide with aryl/alkyl isocyanates. The ureido-substituted benzenesulfonamides showed a very interesting profile for the inhibition of hCAs I and II (cytosolic, off-target isoforms) and hCAs IX and XII (transmembrane, tumor-associated enzymes). The structure-activity relationship for this class of inhibitors was rather complex, but the main features associated with effective inhibition of all these $\alpha$-CAs investigated here have been delineated in detail. The nature of the $\mathrm{R}$ moiety substituting the second ureido nitrogen is the main player in controlling the inhibitory power, probably because of the flexibility of the ureido linker and the possibility of the R group to orientate in different subpockets of the active site cavity of these enzymes. The compounds possessing as $\mathrm{R}$ moiety 4-trifluoromethylphenyl, 2-isopropylphenyl, 2-cyanophenyl, or indan-5-yl were effective hCA I inhibitors with inhibition constants in the range 9.0-10.9 $\mathrm{nM}$. The best hCA II inhibitor was the 2-isopropylphenylsubstituted compound ( $K_{\mathrm{I}}$ of $3.3 \mathrm{nM}$ ), whereas many low nanomolar and subnanomolar hCA IX/XII inhibitors were obtained (e.g., $\mathrm{R}=$ 4-trifluoromethylphenyl, pentafluorophenyl, 4-acetylphenyl, 4-n-butoxyphenyl, 2-cyanophenyl, 3-nitrophenyl, cyclopentyl, indan-5-yl, etc.). One of them, 4-\{[(3'-nitrophenyl)carbamoyl] amino benzenesulfonamide, strongly inhibited the formation of metastases by the highly aggressive 4T1 mammary tumor cells at pharmacologic concentrations of 15-45 $\mathrm{mg} / \mathrm{kg}$, constituting thus an interesting candidate for the development of conceptually novel antimetastatic drugs.

\section{EXPERIMENTAL PROTOCOLS}

Chemistry. ${ }^{1} \mathrm{H},{ }^{13} \mathrm{C}$, and ${ }^{19} \mathrm{~F}$ spectra were recorded using a Bruker Advance III $400 \mathrm{MHz}$ spectrometer. The chemical shifts are reported in parts per million (ppm), and the coupling constants $(J)$ are expressed in hertz $(\mathrm{Hz})$. Infrared spectra were recorded on a Perkin-Elmer Spectrum $\mathrm{R}$ XI spectrometer as solids on $\mathrm{KBr}$ plates. Melting points (mp) were measured in open capillary tubes, unless otherwise stated, using a Büchi B-540 melting point apparatus and are uncorrected. Thin layer chromatography (TLC) was carried out on Merck silica gel $60 \mathrm{~F}_{254}$ aluminum backed plates. Elution of the plates was carried out using ethyl acetate/petroleum ether as the eluting system. Visualization was achieved with UV light at $254 \mathrm{~nm}$ by dipping into a ninhydrin TLC stain solution and heating with a hot air gun. Flash column chromatography was carried out using silica gel (obtained from Aldrich Chemical Co., Milan, Italy). The crude product was introduced into the column as a solution in the same elution solvent system. Solvents and chemicals were used as supplied from Aldrich Chemical Co., Milan, Italy. Purity of the obtained compounds was assessed by HPLC and elemental analysis $(\mathrm{C}, \mathrm{H}, \mathrm{N})$ and was $>95 \%$ for all of the new derivatives reported here.

General Procedure for the Preparation of Compounds 4-30. Sulfanilamide $3(2.90 \mathrm{mmol})$ was dissolved in acetonitrile $(20-$ $30 \mathrm{~mL}$ ) and then treated with a stoichiometric amount of isocyanates A1-A27. The mixture was stirred at room temperature or heated at $50{ }^{\circ} \mathrm{C}$ for $2 \mathrm{~h}$, until completion (TLC monitoring). The heavy precipitate formed was filtered off, washed with diethyl ether $(100 \mathrm{~mL})$, and dried in vacuo. All compounds described here were characterized in detail by spectrosopic and analytic methods (see Supporting Information).

4- $\left\{\left(\left[\left(4^{\prime}\right.\right.\right.\right.$-Acetylphenyl)amino $]$ carbonyl)amino $\}$ benzenesulfonamide (15). White solid; mp $258-260{ }^{\circ} \mathrm{C}$; silica gel TLC $R_{f}=0.27$ (ethyl acetate/petroleum ether 33\%); $\nu_{\max }(\mathrm{KBr}) \mathrm{cm}^{-1}$, 3300 ( $\mathrm{N}-\mathrm{H}$ urea), 1659 ( $\mathrm{C}=\mathrm{O}$ urea), 1590 (aromatic); $\delta_{\mathrm{H}}(400 \mathrm{MHz}$, DMSO- $\left.d_{6}\right) 2.56\left(3 \mathrm{H}, \mathrm{s}, \mathrm{CH}_{3}\right), 7.26\left(2 \mathrm{H}, \mathrm{s}, \mathrm{SO}_{2} \mathrm{NH}_{2}\right), 7.64(2 \mathrm{H}, \mathrm{d}$, $\left.J=8.8,2 \times 2^{\prime}-\mathrm{H}\right), 7.67(2 \mathrm{H}, \mathrm{d}, J=8.8,2 \times 3-\mathrm{H}), 7.79(2 \mathrm{H}, \mathrm{d}, J=8.8,2 \times$ 2-H), $7.96\left(2 \mathrm{H}, \mathrm{d}, J=8.8,2 \times 3^{\prime}-\mathrm{H}\right), 9.22(1 \mathrm{H}, \mathrm{s}, \mathrm{NH}), 9.25(1 \mathrm{H}, \mathrm{s}$, $\mathrm{NH}) ; \delta_{\mathrm{C}}\left(100 \mathrm{MHz}, \mathrm{DMSO}-d_{6}\right) 197.3(\mathrm{C}=\mathrm{O}), 152.9$ (C=O urea), $144.9,143.4,138.2,131.7,130.6,127.8,118.7,118.4,27.3\left(\mathrm{CH}_{3}\right) ; \mathrm{m} / z$ $(\mathrm{ESI}+): 344.36[\mathrm{M}+\mathrm{H}]^{+}, 356.34[\mathrm{M}+\mathrm{Na}]^{+}$. $\mathrm{C}$ atom numbering is as for 4 .

4- $\left\{\left[\left(3^{\prime}\right.\right.\right.$-Nitrophenyl)carbamoyl $]$ amino $\}$ benzenesulfonamide (25). Yellow solid; $44.3 \%$ yield; $\mathrm{mp} 246-248^{\circ} \mathrm{C}$; silica gel TLC $R_{f}=0.39$ (ethyl acetate/petroleum ether $33 \%$ ); $v_{\max }(\mathrm{KBr}) \mathrm{cm}^{-1}, 3370$ $\left(\mathrm{N}-\mathrm{H}\right.$ urea), 1709 ( $\mathrm{C}=\mathrm{O}$ urea), 1592 (aromatic); $\delta_{\mathrm{H}}(400 \mathrm{MHz}$, DMSO- $\left.d_{6}\right) 7.23\left(2 \mathrm{H}, \mathrm{s}, \mathrm{SO}_{2} \mathrm{NH}_{2}\right), 7.59\left(1 \mathrm{H}, \mathrm{dd}, J 8.48 .0,5^{\prime}-\mathrm{H}\right), 7.65$ $(2 \mathrm{H}, \mathrm{d}, J=9.0,2 \times 3-\mathrm{H}), 7.73\left(1 \mathrm{H}, \mathrm{ddd}, J=8.42 .0,0.8,6^{\prime}-\mathrm{H}\right), 7.76(2 \mathrm{H}$, d, $J=9.0,2 \times 2-\mathrm{H}), 7.86\left(1 \mathrm{H}, \mathrm{ddd}, J=8.02 .40 .8,4^{\prime}-\mathrm{H}\right), 8.58(1 \mathrm{H}$, appt, $\left.J=2.2,2^{\prime}-\mathrm{H}\right), 9.25(1 \mathrm{H}, \mathrm{s}, \mathrm{NH}), 9.35(1 \mathrm{H}, \mathrm{s}, \mathrm{NH}) ; \delta_{\mathrm{C}}(100 \mathrm{MHz}$, 
DMSO- $\left.d_{6}\right) 153.2(\mathrm{C}=\mathrm{O}$ urea $), 149.1,143.3,141.6,138.3,131.1,127.7$, 125.5, 118.8, 117.6, 113.3; $\mathrm{m} / z(\mathrm{ESI}+): 359.23[\mathrm{M}+\mathrm{Na}]^{+}$.

CA Inhibition. An Applied Photophysics stopped-flow instrument was used for assaying the $\mathrm{CA}$ catalyzed $\mathrm{CO}_{2}$ hydration activity. ${ }^{15}$ Phenol red (at $0.2 \mathrm{mM}$ ) was used as indicator, working at the absorbance maximum of $557 \mathrm{~nm}$, with $20 \mathrm{mM}$ Hepes (pH 7.4) and $20 \mathrm{mM} \mathrm{NaBF}_{4}$ (for maintaining constant the ionic strength), following the initial rates of the CA-catalyzed $\mathrm{CO}_{2}$ hydration reaction for $10-100 \mathrm{~s}$. The $\mathrm{CO}_{2}$ concentrations ranged from 1.7 to $17 \mathrm{mM}$ for the determination of the kinetic parameters and inhibition constants. For each inhibitor, at least six traces of the initial $5-10 \%$ of the reaction were used for determining the initial velocity. The uncatalyzed rates were determined in the same manner and subtracted from the total observed rates. Stock solutions of inhibitor $(10 \mathrm{mM})$ were prepared in distilled-deionized water, and dilutions up to $0.01 \mathrm{nM}$ were done thereafter with distilled-deionized water. Inhibitor and enzyme solutions were preincubated together for $15 \mathrm{~min}$ at room temperature prior to assay in order to allow for the formation of the $\mathrm{E}-\mathrm{I}$ complex. The inhibition constants were obtained by nonlinear least-squares methods using PRISM 3, whereas the kinetic parameters for the uninhibited enzymes were from Lineweaver-Burk plots, as reported earlier, ${ }^{3}$ and represent the mean from at least three different determinations.

Pharmacological Inhibitors. For in vivo studies, compound 25 was solubilized in $37.5 \%$ PEG $400 / 12.5 \%$ ethanol/50\% saline prior to injection, while compound $\mathbf{1 5}$ was solubilized in 37.5\% PEG400/12.5\% ethanol/10\% Cremophor/40\% saline. Drug aliquots were made fresh daily from powder. Drugs were administered by ip injection using a volume of $200 \mu \mathrm{L}$ for a $20 \mathrm{~g}$ mouse. Specific dosing schedules are described in the appropriate figures.

Experimental Metastasis Assay. All animal studies and procedures were carried out in accordance with protocols approved by the Institution Animal Care Committee at the BC Cancer research Centre and the University of British Columbia (Vancouver, Canada). 4T1 cells $\left(5 \times 10^{5} /\right.$ mouse $)$ were injected directly into the tail vein of $7-9$ weekold female BALB/c mice. Metastatic burden was monitored and quantified using bioluminescent imaging as previously described. ${ }^{21}$ Briefly, mice were imaged $24 \mathrm{~h}$ following the final dose of a given compound. Images showing tumor burden are displayed using a log scale color range, and data were quantified using images acquired for $1 \mathrm{~min}$ at a binning level of 8. Data were analyzed using the contour ROI feature in the Living Image software (Xenogen). Results were subjected to statistical analysis using the Data Analysis ToolPack in Excel software. Two-tailed $p$ values were calculated using Student's $t$ test. Data were considered significant for $p<0.05$.

\section{ASSOCIATED CONTENT}

S Supporting Information. Complete characterization of compounds 4-30 and graphs showing the variation of the mice weight after treatment with $\mathbf{1 5}$ and $\mathbf{2 5}$. This material is available free of charge via the Internet at http://pubs.acs.org.

\section{AUTHOR INFORMATION}

\section{Corresponding Author}

*For S.D.: phone, +39-055-457 3005; fax, +39-055-4573385; e-mail, sdedhar@bccrc.ca. For C.T.S.: phone, (604) 675-8029; fax, (604) 675-8099; e-mail, claudiu.supuran@unifi.it.

\section{ACKNOWLEDGMENT}

Thanks are given to Prof. R. McKenna and M. Aggarwal for the generation of Figure 1 from the PDB files of the CA II-inhibitor adducts.

\section{ABBREVIATIONS USED}

CA, carbonic anhydrase; hCA, human carbonic anhydrase; CAI, carbonic anhydrase inhibitor; $\mathrm{SAR}$, structure-activity relationship

\section{REFERENCES}

(1) (a) Supuran, C. T. Carbonic anhydrases: novel therapeutic applications for inhibitors and activators. Nat. Rev. Drug Discovery 2008, 7, 168-181. (b) Özensoy, O.; De Simone, G.; Supuran, C. T. Drug design studies of the novel antitumor targets carbonic anhydrase IX and XII. Curr. Med. Chem. 2010, 17, 1516-1526. (c) De Simone, G.; Supuran, C. T. Carbonic anhydrase IX: biochemical and crystllographic characterization of a novel antitumor target. Biochim. Biophys. Acta 2010, 1804, 404-409. (d) Supuran, C. T. Carbonic anhydrase inhibitors. Bioorg. Med. Chem. Lett. 2010, 20, 3467-3474.

(2) Alterio, V.; Hilvo, M.; Di Fiore, A.; Supuran, C. T.; Pan, P.; Parkkila, S.; Scaloni, A.; Pastorek, J.; Pastorekova, S.; Pedone, C.; Scozzafava, A.; Monti, S. M.; De Simone, G. Crystal structure of the extracellular catalytic domain of the tumor-associated human carbonic anhydrase IX. Proc. Natl. Acad. Sci. U.S.A. 2009, 106, 16233-16238.

(3) (a) Švastová, E.; Hulíková, A.; Rafajová, M.; Zat'ovičová, M.; Gibadulinová, A.; Casini, A.; Cecchi, A.; Scozzafava, A.; Supuran, C.; Pastorek, J. Hypoxia activates the capacity of tumor-associated carbonic anhydrase IX to acidify extracellular pH. FEBS Lett. 2004, 577, 439-445. (b) Dubois, L.; Douma, K.; Supuran, C. T.; Chiu, R. K.; van Zandvoort, M. A. M. J.; Pastoreková, S.; Scozzafava, A.; Wouters, B. G.; Lambin, P. Imaging the hypoxia surrogate marker CA IX requires expression and catalytic activity for binding fluorescent sulfonamide inhibitors. Radiother. Oncol. 2007, 83, 367-373. (c) Dubois, L.; Lieuwes, N. G.; Maresca, A.; Thiry, A.; Supuran, C. T.; Scozzafava, A.; Wouters, B. G.; Lambin, P. Imaging of CA IX with fluorescent labelled sulfonamides distinguishes hypoxic and (re)-oxygenated cells in a xenograft tumour model. Radiother. Oncol. 2009, 92, 423-428. (d) Wouters, B.G.;; Koritzinsky, M. Hypoxia signalling through $\mathrm{mTOR}$ and the unfolded protein response in cancer. Nat. Rev. Cancer 2008, 8, 851-864.

(4) (a) Swietach, P.; Wigfield, S.; Cobden, P.; Supuran, C. T.; Harris, A. L.; Vaughan-Jones, R. D. Tumor-associated carbonic anhydrase 9 spatially coordinates intracellular $\mathrm{pH}$ in three-dimensional multicellular growth. J. Biol. Chem. 2008, 283, 20473-20483. (b) Swietach, P.; Wigfield, S.; Supuran, C. T.; Harris, A. L.; Vaughan-Jones, R. D. Cancer-associated, hypoxia-inducible carbonic anhydrase IX facilitates $\mathrm{CO}_{2}$ diffusion. BJU Int. 2008, 101 (Suppl. 4), 22-24. (c) Swietach, P.; Hulikova, A.; Vaughan-Jones, R. D.; Harris, A. L. New insights into the physiological role of carbonic anhydrase IX in tumour $\mathrm{pH}$ regulation. Oncogene 2010, 29, 6509-6521.

(5) Chiche, J.; Ilc, K.; Laferrière, J.; Trottier, E.; Dayan, F.; Mazure, N. M.; Brahimi-Horn, M. C.; Pouysségur, J. Hypoxia-inducible carbonic anhydrase IX and XII promote tumor cell growth by counteracting acidosis through the regulation of the intracellular pH. Cancer Res. 2009, 69, 358-368.

(6) (a) Ahlskog, J. K. J.; Dumelin, C. E.; Trüssel, S.; Marlind, J.; Neri, D. In vivo targeting of tumor-associated carbonic anhydrases using acetazolamide derivatives. Bioorg. Med. Chem. Lett. 2009, 19, 4851-4856. (b) Ahlskog, J. K.; Schliemann, C.; Mårlind, J.; Qureshi, U.; Ammar, A.; Pedleym, R. B.; Neri, D. Human monoclonal antibodies targeting carbonic anhydrase IX for the molecular imaging of hypoxic regions in solid tumours. Br. J. Cancer. 2009, 101, 645-657.

(7) Hilvo, M.; Baranauskiene, L.; Salzano, A. M.; Scaloni, A.; Matulis, D.; Innocenti, A.; Scozzafava, A.; Monti, S. M.; Di Fiore, A.; De Simone, G.; Lindfors, M.; Janis, J.; Valjakka, J.; Pastorekova, S.; Pastorek, J.; Kulomaa, M. S.; Nordlund, H. R.; Supuran, C. T.; Parkkila, S. Biochemical characterization of CA IX: one of the most active carbonic anhydrase isozymes. J. Biol. Chem. 2008, 283, 27799-27809.

(8) (a) Wykoff, C. C.; Beasley, N. J.; Watson, P. H.; Turner, K. J.; Pastorek, J.; Sibtain, A.; Wilson, G. D.; Turley, H.; Talks, K. L.; Maxwell, P. H.; Pugh, C. W.; Ratcliffe, P. J.; Harris, A. L. Hypoxia-inducible expression of tumor-associated carbonic anhydrases. Cancer Res. 2000, 
60, 7075-7083. (b) Bartosova, M.; Parkkila, S.; Pohlodek, K.; Karttunen, T. J.; Galbavy, S.; Mucha, V.; Harris, A. L.; Pastorek, J.; Pastorekova, S. Expression of carbonic anhydrase IX in breast is associated with malignant tissues and is related to overexpression of c-erbB2. J. Pathol. 2002, 197, 1-8.(c) Pastoreková, S.; Pastorek, J. Cancer-Related Carbonic Anhydrase Isozymes and Their Inhibition. In Carbonic Anhydrase: Its Inhibitors and Activators; Supuran, C. T., Scozzafava, A., Conway, J., Eds.; CRC Press: Boca Raton, FL, 2004; pp 255-281. (d) Ebbesen, P.; Pettersen, E. O.; Gorr, T. A.; Jobst, G.; Williams, K.; Kienninger, J.; Wenger, R. H.; Pastorekova, S.; Dubois, L.; Lambin, P.; Wouters, B. G.; Supuran, C. T.; Poellinger, L.; Ratcliffe, P.; Kanopka, A.; Görlach, A.; Gasmann, M.; Harris, A. L.; Maxwell, P.; Scozzafava, A. Taking advantage of tumor cell adaptations to hypoxia for developing new tumor markers and treatment strategies. J. Enzyme Inhib. Med. Chem. 2009, 24 (S1), 1-39.

(9) (a) Said, H. M.; Supuran, C. T.; Hageman, C.; Staab, A.; Polat, B.; Katzer, A.; Scozzafava, A.; Anacker, J.; Flentje, M.; Vordermark, D. Modulation of carbonic anhydrase 9 (CA9) in human brain cancer. Curr. Pharm. Des. 2010, 16, 3288-3299. (b) Zatovicova, M; Jelenska, L; Hulikova, A; Csaderova, L; Ditte, Z; Ditte, P; Goliasova, T; Pastorek, J; Pastorekova, S. Carbonic anhydrase IX as an Anticancer therapy target: preclinical evaluation of internalizing monoclonal antibody directed to catalytic domain. Curr. Pharm. Des. 2010, 16, 3255-3263.

(10) Pacchiano, F.; Aggarwal, M.; Avvaru, B. S.; Robbins, A. H.; Scozzafava, A.; McKenna, R.; Supuran, C. T. Selective hydrophobic pocket binding observed within the carbonic anhydrase II active site accommodate different 4-substituted-ureido-benzenesulfonamides and correlate to inhibitor potency. Chem. Commun. (Cambridge, U. K.) 2010, 46, 8371-8373.

(11) Roth, J. S.; Degering, E. F. The preparation of sulfanilamide derivatives containing a urea or thiourea grouping. J. Am. Chem. Soc. 1945, 67, 126-128.

(12) (a) Supuran, C. T.; Scozzafava, A.; Jurca, B. C.; Ilies, M. A. Carbonic anhydrase inhibitors. Part 49. Synthesis of substituted ureidoand thioureido derivatives of aromatic/heterocyclic sulfonamides with increased affinities for isozyme I. Eur. J. Med. Chem. 1998, 33, 83-93. (b) Scozzafava, A.; Supuran, C. T. Carbonic anhydrase inhibitors. Arylsulfonylureido and arylureido-substituted aromatic and heterocyclic sulfonamides: towards selective inhibitors of carbonic anhydrase isozyme I. J. Enzyme Inhib. 1999, 14, 343-363.

(13) Alterio, V.; Di Fiore, A.; D’Ambrosio, K.; Supuran, C. T.; De Simone, G. X-Ray Crystallography of CA inhibitors and Its Importance in Drug Design. In Drug Design of Zinc-Enzyme Inhibitors: Functional, Structural, and Disease Applications; Supuran, C. T., Winum, J. Y., Eds.; Wiley: Hoboken, NJ, 2009; pp 73-138.

(14) (a) Avvaru, B. S.; Wagner, J. M.; Maresca, A.; Scozzafava, A.; Robbins, A. H.; Supuran, C. T.; McKenna, R. Carbonic anhydrase inhibitors. The X-ray crystal structure of human isoform II in adduct with an adamantyl analogue of acetazolamide resides in a new hydrophobic binding pocket. Bioorg. Med. Chem. Lett. 2010, 20, 4376-4381. (b) Di Fiore, A.; Monti, S. M.; Innocenti, A.; Winum, J.-Y.; De Simone, G.; Supuran, C. T. Carbonic anhydrase inhibitors. X-ray crystallographic and solution binding studies for the interaction of a boron containing aromatic sulfamide with mammalian isoforms I-XV. Bioorg. Med. Chem. Lett. 2010, 20, 3601-3605. (c) Wagner, J.; Avvaru, B. S.; Robbins, A. H.; Scozzafava, A.; Supuran, C. T.; McKenna, R. Coumarinyl-substituted sulfonamides strongly inhibit several human carbonic anhydrase isoforms: solution and crystallographic investigations. Bioorg. Med. Chem. 2010, 18, 4873-4878.

(15) Khalifah, R. G. The carbon dioxide hydration activity of carbonic anhydrase. I. Stop-flow kinetic studies on the native human isoenzymes B and C. J. Biol. Chem. 1971, 246, 2561-2573.

(16) (a) Chen, C. L.; Chu, J. S.; Su, W. C.; Huang, S. C.; Lee, W. Y. Hypoxia and metabolic phenotypes during breast carcinogenesis: expression of HIF-1alpha, GLUT1, and CAIX. Virchows Arch. 2010, 457, 53-61. (b) Kristiansen, G.; Rose, M.; Geisler, C.; Fritzsche, F. R.; Gerhardt, J.; Luke, C.; Ladhoff, A. M.; Knuchel, R.; Dietel, M.; Moch, H.; Varga, Z.; Theurillat, J. P.; Gorr, T. A.; Dahl, E. Endogenous myoglobin in human breast cancer is a hallmark of luminal cancer phenotype. $\mathrm{Br}$. J. Cancer 2010, 102, 1736-1745.

(17) (a) Chia, S. K.; Wykoff, C. C.; Watson, P. H.; Han, C.; Leek, R. D.; Pastorek, J.; Gatter, K. C.; Ratcliffe, P.; Harris, A. L. Prognostic significance of a novel hypoxia-regulated marker, carbonic anhydrase IX, in invasive breast carcinoma. J. Clin. Oncol. 2001, 19, 3660-3668. (b) Hussain, S. A.; Ganesan, R.; Reynolds, G.; Gross, L.; Stevens, A.; Pastorek, J.; Murray, P. G.; Perunovic, B.; Anwar, M. S.; Billingham, L.; James, N. D.; Spooner, D.; Poole, C. J.; Rea, D. W.; Palmer, D. H. Hypoxia-regulated carbonic anhydrase IX expression is associated with poor survival in patients with invasive breast cancer. Br. J. Cancer 2007, 96, 104-109.

(18) (a) Aslakson, C. J.; Miller, F. R. Selective events in the metastatic process defined by analysis of the sequential dissemination of subpopulations of a mouse mammary tumor. Cancer Res. 1992, 52, 1399-1405. (b) Heppner, G. H.; Miller, F. R.; Shekhar, P. M. Nontransgenic models of breast cancer. Breast Cancer Res. 2000, 2, 331-334. (c) Eckhardt, B. L.; Parker, B. S.; van Laar, R. K.; Restall, C. M.; Natoli, A. L.; Tavaria, M. D.; Stanley, K. L.; Sloan, E. K.; Moseley, J. M.; Anderson, R. L. Genomic analysis of a spontaneous model of breast cancer metastasis to bone reveals a role for the extracellular matrix. Mol. Cancer Res. 2005, 3, 1-13.

(19) (a) Pulaski, B. A.; Ostrand-Rosenberg, S. Mouse 4T1 breast tumor model. Curr. Protoc. Immunol. 2001, 20, 202-212. (b) Tao, K.; Fang, M.; Alroy, J.; Sahagian, G. G. Imagable 4T1 model for the study of late stage breast cancer. BMC Cancer 2008, 8, 228.

(20) Lou, Y.; Preobrazhenska, O.; auf dem Keller, U.; Sutcliffe, M.; Barclay, L.; McDonald, P. C.; Roskelley, C.; Overall, C. M.; Dedhar, S. Epithelial-mesenchymal transition (EMT) is not sufficient for spontaneous murine breast cancer metastasis. Dev. Dyn. 2008, 237, 2755-2768.

(21) Ebos, J. M.; Lee, C. R.; Cruz-Munoz, W.; Bjarnason, G. A.; Christensen, J. G.; Kerbel, R. S. Accelerated metastasis after short-term treatment with a potent inhibitor of tumor angiogenesis. Cancer Cell 2009, 15, 232-239. 